\title{
Serenoa repens associated with selenium and lycopene extract and bromelain and methylsulfonylmethane extract are able to improve the efficacy of levofloxacin in chronic bacterial prostatitis patients
}

\author{
Tommaso Cai ${ }^{1}$, Daniele Tiscione ${ }^{1}$, Luca Gallelli ${ }^{2}$, Paolo Verze ${ }^{3}$, Alessandro Palmieri ${ }^{3}$, \\ Vincenzo Mirone ${ }^{3}$, Riccardo Bartoletti ${ }^{4}$, Gianni Malossini ${ }^{1}$ \\ ${ }^{1}$ Department of Urology, Santa Chiara Regional Hospital, Trento, Italy; \\ ${ }^{2}$ Department of Health Science, School of Medicine, University of Catanzaro, Catanzaro, Italy; \\ ${ }^{3}$ Department of Urology, University of Naples, Federico II, Naples, Italy; \\ ${ }^{4}$ Department of Urology, University of Pisa, Pisa, Italy.
}

\section{Summary Objective: To date, the management of patients with chronic bacterial prostatitis} (CBP) is not satisfactory, especially in terms of symptoms relief. Here, we evaluated the efficacy and the safety of a combination of serenoa repens, selenium and lycopene extract + bromelain and methylsulfonylmethane extract associated with levofloxacin in patients with CBP.

Materials and methods: All patients with clinical and instrumental diagnosis of CBP, admitted to a single Urological Institution from March to June 2015 were enrolled in this phase III study. All enrolled patients were randomized into two groups: Group A received levofloxacin $500 \mathrm{mg}$ o.d. for 14 days associated with lycopene and methylsulfonylmethane; Group B received levofloxacin (500 mg o.d. for 14 days) only. Clinical and microbiological analyses were carried out at the time of admission (T0) and during the followups at 1 month (T1) and 6 months (T2) from the end of the treatment. NIH Chronic Prostatitis Symptom Index (CPSI), International Prostatic Symptom Score (IPSS) and Quality of Well-Being (2oL) questionnaires were used. The main outcome measures were the rate of microbiological cure and the improvement in questionnaire results from baseline at the end of the follow-ups period.

Results: Forty patients were enrolled in Group A and 39 in Group B. During the follow-up (T1), we recorded a significant changes in terms of NIH-CPSI and IPSS in Group A (mean difference: $17.6 \pm 2.65 ; 12.2 \pm 2.33$; $p<0.01$; $p<$ 0.05 , respectively) and versus Group $B$ at the intergroup analysis (mean difference: $-9 \pm 1.82 ;-8.33 \pm 1.71 ; p<0.05$; $p<0.05$, respectively). No differences were reported in terms of microbiological findings between the two groups. At the second follow-up visit (T2), questionnaire results demonstrated statistically significant differences between groups $(p<0.001)$. One patient in Group A $(2.5 \%)$ and 7 patients (17.9\%) in Group B showed a symptomatic and microbiological recurrence $(p=0.02)$.

Conclusions: The combination of serenoa repens, selenium, lycopene + bromelain and methylsulfonylmethane extracts improved the clinical efficacy of levofloxacin in patients affected by CBP without the development of side effects.

KEY WORDS: Chronic bacterial prostatitis; Levofloxacin; Serenoa repens; Bromelain.

Submitted 15 January 2016; Accepted 6 March 2016

\section{INTRODUCTION}

Even if the prevalence of chronic bacterial prostatitis (CBP), category II according to the National Institutes of Health (NIH) classification of Chronic Prostatitis-Chronic Pelvic Pain Syndrome, ranges in Europe between 7 and $14 \%$ of all cases with prostatitis (1-2), the impact on patient's quality of life is high (3-4). Although a long-term antibiotic treatment with fluorquinolones represents the gold standard therapy for CBP (5), short-term recurrences and drug-related adverse events are frequently reported (6-7). In this sense, the use of phytotherapy to both alleviate symptoms related to $\mathrm{CBP}$ and decrease the rate of symptomatic recurrence is nowadays increasing. It seems related toseveral reasons, e.g. low side-effect and costs (8), high level of adherence (9) and a low rate of efficacy of standard treatments with subsequent patient disappointment and drop-out (10). Several phytotherapeutic compounds have recently been investigated to treat or prevent bacterial prostatitis, such as Serenoa repens, Urtica dioica, or other compounds such as curcumin (11-13). Here, we focused our attention on Serenoa repens, selenium, lycopene, bromelain and methylsulfonylmethane extracts. The role of Serenoa repens, selenium and lycopene is well discussed in the current literature, with convinced results about their efficacy in the treatment of patients with prostatitis (11, 14-15). Recently, Marzano et al. showed the efficacy of a compound with bromelain in improving urinary symptoms related to benign prostatic hyperplasia (16). The efficacy of bromelain on prostatic symptoms is probably due to its anti-inflammatory effect by increasing the production of anti-inflammatory prostaglandins such as TNF-alfa or interleukin (IL)-6 (17)

Methylsulfonylmethane, also known as dimethylsulfone and methylsulfone, shows several positive effects on a variety conditions, such as osteoarthritis and allergic rhinitis (18). It is well known that IL- 6 production is rapidly increased in acute inflammatory responses associated with infection, trauma, and other stresses (17). However, high-levels of IL-6 could induce an inflammatory state. Karlsen et al. demonstrated that methylsulfonylmethane inhibits IL-6

No conflict of interest declared. 
production in macrophage cells, and reduces plasma levels of IL-6 in animal model (17). On the basis of these evidences, the use of an association between antibiotic and anti-inflammatory compounds could represents a good option for the treatment of CBP patients.

Therefore, in the present study we evaluated the efficacy and the safety of a combination of Serenoa repens, selenium, lycopene (PROSTADEP PLUS ${ }^{\circledR}$ ) and bromelain, methylsulfonylmethane (ZACHELASE ${ }^{\circledR}$ ) associated with levofloxacin, to improve quality of life in patients with CBP.

\section{Patients AND MEthods}

\section{Study design}

We performed a randomized, prospective, open-label, and parallel groups study in a single urological institution between March and June 2015. The study was conducted according to the ethical principles of the Declaration of Helsinki and the protocol was approved by an independent ethics committee. Before the beginning of the study, all participants signed the written informed consent. No placebo run-in period was considered necessary for the treatment of patients with urinary culture positivity.

\section{Experimental protocol}

All consecutive patients presented us for symptoms related to CBP and post-prostate massage urine culture positive for uropathogens were enrolled in this study. At the time of admission ( $\mathrm{TO}$ ), the patients underwent selfadministered baseline questionnaire [NIH-Chronic Prostatitis Symptom Index (NIH-CPSI) and International Prostatic Symptom Score (IPSS)], urological examination with history interview and Meares-Stamey test performed by the same urologist (TC) in agreement with the European Association of Urology (EAU) guidelines (5). All patients underwent two follow-ups at 1 month (T1) and 6 months (T2) from the end of therapy. During each followup all patients underwent NIH-CPSI, IPSS questionnaires and urological examination. The Meares-Stamey test was carried-out only in patients with symptomatic recurrence. In agreement with our previous papers, the patients that were positive to Meares-Stamey test for uropathogens were treated with other antibiotics depending on the organism and its susceptibility profile $(3,11)$.

\section{Inclusion and exclusion criteria}

The primary inclusion criteria were age between 18 and 45 years and the following conditions: the presence of symptoms related to CBP for at least 3 months (5) and a positive Meares-Stamey 4-glass test with first voided urine, midstream urine, prostatic secretion and a VB3 urine culture, which had to be $\geq 103$ colony forming units (CFU)/mL of uropathogens $(5,20)$. Patients with demonstrated or suspected allergy to fluoroquinolones or other compounds contained in the treatments were excluded. Moreover, patients treated in the last 4 weekswith antibiotics were also excluded. Patients with positive tests for atypical or sexually transmitted diseases, such as Chlamydia trachomatis, Ureaplasma urealiticum, or Neisseria gonorrhoeae were excluded. In order to obtain an homogenous group to analyze the following bacteria were considered as uropathogens, in accordance with Trinchieri: enteric Gramnegative rods; enterococci, Staphylococcus saprophyticus; and group B streptococci (20).

\section{Questionnaires and urological examinations}

The validated Italian versions of the NIH Chronic Prostatitis Symptom Index (NIH-CPSI) (21) and the International Prostatic Symptom Score (IPSS) (22) were administered to each patient. The questionnaire was selfadministered when the patient arrived at the Centre.

\section{Figure 1.}

The figure shows the study schedule.

IPSS: International Prostatic Symptom Score; NIH-CPSI: NIH Chronic Prostatitis Symptom Index; QoL: Quality of Well-Being. V1: visit 1, at the enrolment; V2: visit 2 at the first follow-up; V3: visit 3 at the second follow-up.

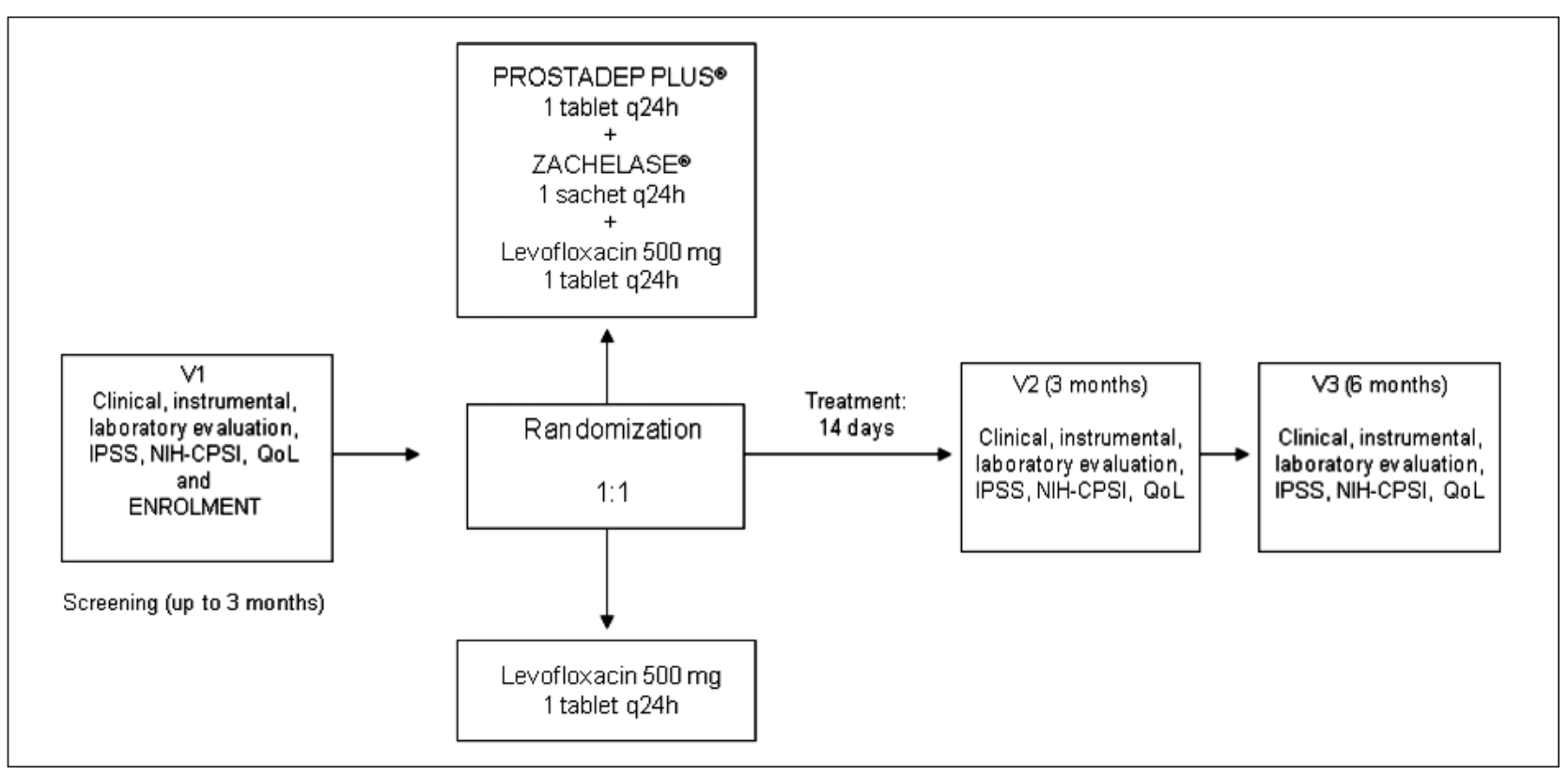


Moreover, patient quality of life was measured by using an Italian version of the Quality of Well-Being, a validated, multiattribute health scale (23). This scale was selected because it has been successfully applied to acute illnesses, whereas other quality of life scales, including the Short Form-36 (SF-36) Health Survey, are more suitable in chronic cases. Higher scores on the QoL scale reflect a higher quality of life (24). In accordance with the study by Nickel et al., prostatitis-like symptoms were considered significant at a pain score of $\geq 4$. The NIH-CPSI was also used in determining clinical therapy efficacy (25).

\section{Microbiological considerations}

In line with our previous study, the biological samples collected during the urological examination and during the Meares-Stamey test were immediately taken to the laboratory, under refrigerated conditions, and analyzed for cultures (11). Microbiological culture was carried out in accordance with the methods described by Motrich (26) and Mazzoli (27).

\section{Assignment to the groups}

Patients with CBP and without regard for age, or medical history were randomly allocated to receive either one tablet of levofloxacin (500 mg o.d. orally) for 14 days in association with a tablet of PROSTADEP PLUS ${ }^{\circledR}$ in the morning and a sachet of ZACHELASE ${ }^{\circledR}$ in the evening (Group A); or one tablet of levofloxacin (500 mg o.d. orally) for 14 days alone (Group B). The randomization was performed in agreement with our previous studies (28-30). Briefly we used a computer program to generate a sequence of treat- ment allocations by block randomization using a random number generator. Investigators were blinded to the block size to avoid selection bias.

The study design is displayed in Figure 1. We used a treatment course of 14 days to reduce the development of adverse effects related to a long course of treatment (19). The adverse events were evaluated in agreement with the common terminology criteria for adverse events (CTCAE) guidelines. Safety assessments included treatment-emergent adverse events (TEAEs) and serious AEs (SAEs).

\section{Composition and characterization of the extracts used PROSTADEP PLUS ${ }^{\circledR}$}

Each tablet contains SABAMAX ${ }^{\circledR}$ [Serenoa repens 600 (537 mg), Selenium L-methionine 55 mcg and Lycopene (Solanum lycopersicum L.) $4 \mathrm{mg}$.

\section{ZACHELASE $^{\circledR}$}

Each sachet contains bromelain (500 mg; 1.250 units), methylsulfonylmethane $900 \mathrm{mg}$ and ascorbid acid $500 \mathrm{mg}$.

\section{End points}

The first end-point was the rate of microbiological cure and the improvement in questionnaire results recorded during the follow-up (T2-TO; T1-T0). We considered that a treatment have a clinical efficacy when a patient is asymptomatic for at least 2 weeks after the end of the treatment. Clinical failure was defined as the persistence of clinical symptoms after treatment or the suspension of therapy for significant reported adverse effects. In addition, spontaneously reported adverse events or those noted by the investigator were recorded during the whole study period.

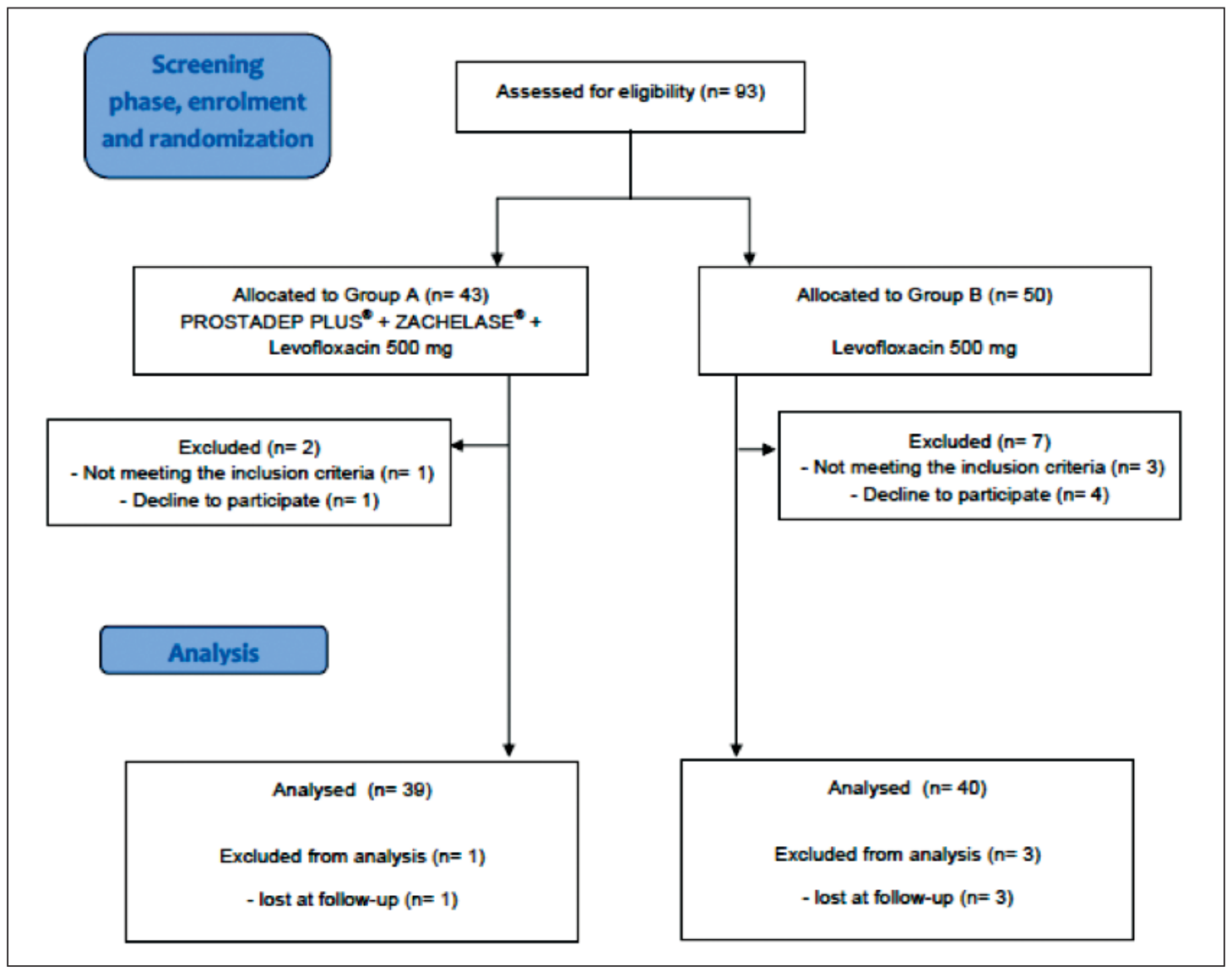

Figure 2. The figure shows the study flow-chart in line with the CONSORT guidelines. 


\section{Statistical analysis}

The required sample size for the present study was calculated under the following conditions: Difference between the groups, $2 \pm 1$ score points in the NIH-CPSI pain domain; $\alpha$ error level, 0.05 two-sided; statistical power, $80 \%$; and anticipated effect size, Cohen's $d=0.5$. The calculation yielded $2 \times 39$ individuals per group. At baseline, the independent sample 2-tailed t-test was used to compare variables. For categorical parameters, chi-square test was applied.

Changes from baseline to end of therapy were analyzed using ranked one-way analysis of variance (ANOVA) with a term for treatment group. All data are expressed as mean \pm standard deviation (SD). The threshold of statistical significance was set at $p<0.05$.

All reported p-values are two-sided. All statistical analyses were performed by using SPSS 21.0 (IBM Corporation, Armonk, NY, USA), while G*Power (Institut für Experimentelle Psychologie, Heinrich Heine Universität, Dusseldorf, Germany) was used for power calculation.

\section{RESULTS}

\section{Patients}

During the study period, 83 patients were enrolled and randomized in two groups: 40 in the group A and 43 in the group B. One patient in Group A and 3 in Group B were lost during the follow-up. Finally, 39 patients in group A and 40 patients in group B completed the study protocol (mean age $34.8 \pm 5.11$ years). The flow chart of this study is presented in Figure 2.

\section{Baseline characteristics}

History, clinical and questionnaires data at the time of admission are reported in Table 1. We did not record any difference in terms of symptoms or bacterial strains prevalence between the two groups.

\section{Follow-up examination}

During the first follow-up (T1), we recorded a significant difference in terms of NIH-CPSI and IPSS in the Group A (mean difference: $17.6 \pm 2.65 ; 12.2 \pm 2.33 ; \mathrm{p}<0.01 ; \mathrm{p}<$ 0.05 , respectively) and versus Group B at the intergroup analysis (mean difference: $-9 \pm 1.82 ;-8.33 \pm 1.71$; $\mathrm{p}<$ $0.05 ; \mathrm{p}<0.05$, respectively) (Table 2 ). No differences were reported in terms of microbiological cure between the two groups. During the second follow-up (T2), questionnaire results demonstrated statistically significant differences between groups (all p $<0.001$ ). One patient in Group A (2.5\%) and 7 in Group B (17.9\%) showed a microbiologically demonstrated symptomatic recurrence $(p=0.02)$. Significant differences were found at the intergroup analysis when we consider the outcome measures and the QoL (Figure 3).

\section{Adverse events}

All subjects correctly took the treatments showing a $100 \%$ of adherence to the treatment a $100 \%$ of compliance to the experimental protocol. Two patients, 1 (2.5\%) in Group A and 1 in Group B (2.6\%) developed mild adverse effects (nausea) that did not require drug discontinuation or other treatments.
Table 1.

Clinical, instrumental and laboratory patient's data at the enrolment time.

\begin{tabular}{|c|c|c|}
\hline & $\begin{array}{c}\text { Group A } \\
\text { mean (SD* or \%) }\end{array}$ & $\begin{array}{c}\text { Group B } \\
\text { mean (SD* or \%) }\end{array}$ \\
\hline Patients $\left(n^{\circ}\right)$ & 39 & 40 \\
\hline Age & $34.1 \pm 4.58$ & $35.0 \pm 5.67$ \\
\hline $\begin{array}{l}\text { Marital Status } \\
\text { married } \\
\text { unmarried }\end{array}$ & $\begin{array}{l}15(38.4) \\
24(61.6)\end{array}$ & $\begin{array}{l}16(40.0) \\
24(60.0)\end{array}$ \\
\hline $\begin{array}{l}\text { Educational qualification } \\
\text { Primary school } \\
\text { High school } \\
\text { University }\end{array}$ & $\begin{array}{l}- \\
29(74.3) \\
10(25.7)\end{array}$ & $\begin{array}{c}- \\
28(70.0) \\
12(30.0)\end{array}$ \\
\hline $\begin{array}{l}\text { Smooking } \\
\text { Yes } \\
\text { No }\end{array}$ & $\begin{array}{l}27(69.2) \\
12(30.8)\end{array}$ & $\begin{array}{l}30(75.0) \\
10(25.0)\end{array}$ \\
\hline Sexually active (past month) & $39(100)$ & $40(100)$ \\
\hline $\begin{array}{l}\text { Sexual behaviour } \\
1 \text { partner } \\
>1 \text { partners } \\
\end{array}$ & $\begin{array}{c}38(97.5) \\
1(2.5)\end{array}$ & $\begin{array}{c}38(95.0) \\
2(5.0)\end{array}$ \\
\hline $\begin{array}{l}\text { Contraceptive use } \\
\text { Condom } \\
\text { Coitus interruptus }\end{array}$ & $\begin{array}{l}29(74.3) \\
10(25.7)\end{array}$ & $\begin{array}{c}32(80.0) \\
8(20.0)\end{array}$ \\
\hline Start of CP\# history (months) & $21.3 \pm 6.21$ & $20.8 \pm 7.01$ \\
\hline $\begin{array}{l}\text { Symptoms score at baseline (m } \\
\text { NIH-CPSI§ } \\
\text { IPSS } † \\
\text { QoL } † \\
\end{array}$ & $\begin{array}{l}\text { (range) } \\
19.94 \pm 2.1 \\
17.35 \pm 3.4 \\
0.55 \pm 0.15 \\
\end{array}$ & $\begin{array}{l}19.75 \pm 3.9 \\
18.65 \pm 3.1 \\
0.56 \pm 0.18\end{array}$ \\
\hline $\begin{array}{l}\text { Clinical presentation } \\
\text { Dysuria } \\
\text { Urgency } \\
\text { Dysuria + frequency } \\
\text { Burning } \\
\end{array}$ & $\begin{array}{c}21(53.9) \\
2(5.1) \\
4(10.2) \\
12(30.8)\end{array}$ & $\begin{array}{c}21(52.5) \\
3(7.5) \\
5(12.5) \\
11(27.5)\end{array}$ \\
\hline $\begin{array}{l}\text { Microbiological results } \\
\text { E. coli } \\
\text { Enterococcus facealis } \\
\text { Other uropathogens } \\
\end{array}$ & $\begin{array}{c}22(56.4) \\
11(28.2) \\
6(15.4)\end{array}$ & $\begin{array}{c}24(60.0) \\
4(20.0) \\
8(20.0) \\
\end{array}$ \\
\hline $\begin{array}{l}\text { The table shows all anamnestic, } \\
\text { SD*: Standard Deviation; CP\#: } \\
\text { Symptom Index; IPSS }+ \text { Internat } \\
\text { QoL‡: Quality of Well-Being. }\end{array}$ & $\begin{array}{l}\text { al and questionr } \\
\text { c prostatitis; NIH } \\
\text { Prostatic Sympto }\end{array}$ & $\begin{array}{l}\text { a at enrolment. } \\
\text { IIH Chronic Prostatit }\end{array}$ \\
\hline
\end{tabular}

Table 2.

Questionnaire results at the first follow-up visit.

\begin{tabular}{|c|c|c|}
\hline & $\begin{array}{c}\text { Group A } \\
\text { difference from baseline } \\
\text { (SD* or \%) }\end{array}$ & $\begin{array}{c}\text { Group B } \\
\text { difference from baseline } \\
\text { (SD* or \%) }\end{array}$ \\
\hline $\begin{array}{l}\text { Efficacy outcomes } \\
\text { NIH-CPSI }\end{array}$ & $17.6 \pm 2.65$ & $8.4 \pm 3.1$ \\
\hline $\begin{array}{l}\text { Treatment difference } \\
\text { IPSS\# }\end{array}$ & \multicolumn{2}{|c|}{$-9 \pm 1.82$} \\
\hline $\begin{array}{l}\text { Treatment difference } \\
\text { QoL§ }\end{array}$ & \multicolumn{2}{|c|}{$-8.33 \pm 1.71$} \\
\hline Treatment difference & \multicolumn{2}{|c|}{$0.17 \pm 0.03$} \\
\hline $\begin{array}{l}\text { The table shows the } \\
\text { to main outcome mea } \\
\text { IPSS+: International P }\end{array}$ & $\begin{array}{l}\text { change differences from } \\
\text { s. NIH-CPSI§: NIH Chronic } \\
\text { atic Symptom Score; QoL }\end{array}$ & $\begin{array}{l}6 \text { months relative } \\
\text { Symptom Index; } \\
\text { f Well-Being. }\end{array}$ \\
\hline
\end{tabular}

\section{Discussion}

Even if CBP has an important impact on patient's quality of life, a highly satisfactory treatment in terms of efficacy and safety still needs. CBP continues to pose a treatment challenge for all urologists and for these reasons, a lot of non-standardized treatment schedule, sometimes in off- 
Figure 3.

The figure shows the differences in terms of questionnaires results (§ NIH-CPSI; * IPSS) between the two groups. V2: visit at the second follow-up (6 months).

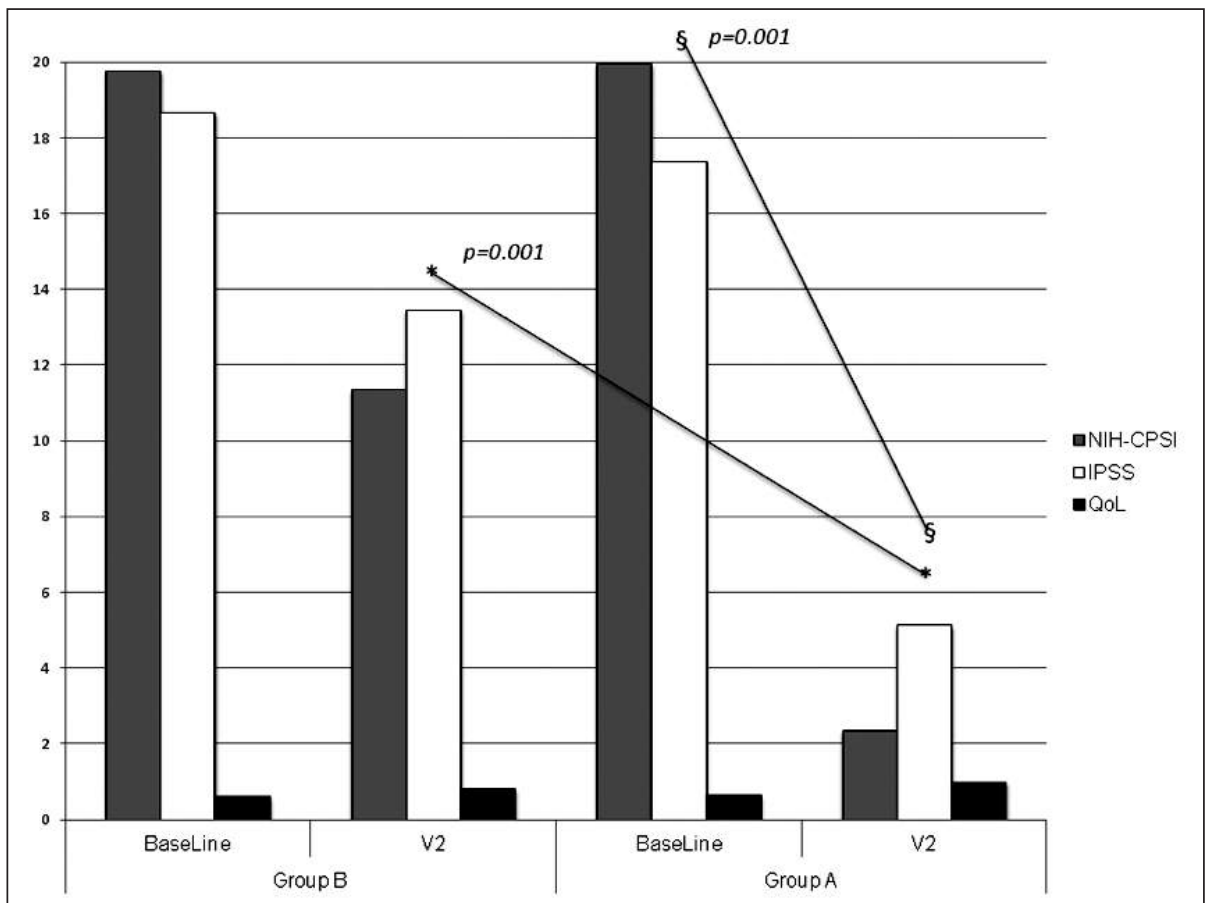

the fact that several extracts are able to inhibit many inflammatory pathways involved in the complex pathogenesis of the disease.

However, even if our results are encouraging, this study shows some limitations, particularly the shot time of observation. In fact, it is very important to highlight that the safety of phytotherapy should be evaluated with a long-term follow-up, in order to discover delayed adverse side effects

The use of a short-term antibiotic treatment period ( 14 days) should not be considered a limitation of the study because we had choice this time in agreement with the paper of Bjerklund Johansen et al., that documented the minimum duration of antibiotic treatment should be $2-4$ weeks (33). label way, were offered to the patients. Here, we demonstrated that the use of combination of Serenoa repens, selenium, lycopene (PROSTADEP PLUS ${ }^{\circledR}$ ) and bromelain, methylsulfonylmethane (ZACHELASE ${ }^{\circledR}$ ) extracts is able to improve the clinical efficacy of levofloxacin in patients affected by CBP, by improving their level of quality of life. Moreover, we demonstrated a high level of treatment compliancethat may be related with the low frequency of adverse events and with the improvement of QoL. The improvement in QoL should be due to the anti-inflammatory effect of bromealin and methylsulfonylmethane extracts (16-17). Several Authors have demonstrated the anti-inflammtory effects of these compounds, especially in patients with severe symptoms. It is probably due to the effect of methylsulfonylmethane in IL-6 reduction, as demonstrated in other pathological conditions (17-18). The effect of Serenoa repens of prostate tissue can contribute to improve the patient's QoL and relief the pain. Several Authors demonstrated that Serenoa repens shows a potent anti-inflammatory properties in the whole prostate tissue (31) and is able to inhibit MCP-1/CCL2 and VCAM-1 expression by human prostate and vascular cells in an inflammatory environment, modulating the inflammatory response (32).

However, our results are probably due to synergic efficacy of all compounds, in fact it has been well documented that quinolones have antibiotic as well as immunemodulatory effects and are able to decrease the production of pro-inflammatory cytokines (15).

In this concern it is not easy to evaluate the efficacy of each single compound on the QoL improvement in CBP patients.

Finally, we believe that the phytotherapy could be an interesting multimodal approach to CBP patients due to

\section{Conclusion}

In our study, we demonstrated that combination of Serenoa repens, selenium, lycopene (PROSTADEP PLUS ${ }^{\circledR}$ ) and bromelain, methylsulfonylmethane (ZACHELASE ${ }^{\circledR}$ ) extracts is able to improve the clinical efficacy of levofloxacin in patients affected by chronic bacterial prostatitis, without the development of adverse drug reactions.

\section{ACKNOWLEDGEMENTS}

We are grateful to Professor John Denton (Department of Modern Philology, University of Florence) for manuscript language revision.

\section{Contributions}

TC, DT, data collecting and analyzing; TC, LG, PV manuscript writing; GM, RB, AP, VM supervision.

\section{REFERENCES}

1. Bartoletti R, Cai T, Mondaini N, et al. Prevalence, incidence estimation, risk factors and characterization of chronic prostatitis/chronic pelvic pain syndrome in urological hospital outpatients in Italy: results of a multi center case-control observational study. J Urol. 2007; 178:2411-2415.

2. Cai T, Mazzoli S, Meacci F, et al. Epidemiological features and resistance pattern in uropathogens isolated from chronic bacterial prostatitis. J Microbiol. 2011; 49:448-54.

3. Bartoletti R, Cai T, Nesi G, et al. The impact of biofilm-producing bacteria on chronic bacterial prostatitis treatment: results from a longitudinal cohort study. World J Urol. 2014; 32:737-42.

4. Magri V, Perletti G, Bartoletti R, et al. Critical issues in chronic prostatitis. Arch Ital Urol Androl. 2010; 82:75-82. 
5. European Association of Urology Guidelines on Urological Infections. 2014. http://uroweb.org/wp-content/uploads/19-Urologicalinfections_LR2.pdf

6. Lee YS, Han CH, Kang SH, et al. Synergistic effect between catechin and ciprofloxacin on chronic bacterial prostatitis rat model. Int J Urol. 2005; 12:383-9.

7. Naber KG. Antimicrobial treatment of bacterial prostatitis. Eur Urol. 2003; 43:23-26.

8. Wilt T, Mac Donald R, Ishani A, et al. Cernilton for benign prostatic hyperplasia. Cochrane Database Syst Rev 2000. CD001042.

9. Cai T, Wagenlehner FM, Luciani LG, et al. Pollen extract in association with vitamins provides early pain relief in patients affected by chronic prostatitis/chronic pelvic pain syndrome. Exp Ther Med 2014; 8:1032-1038.

10. Shoskes DA. Phytotherapy in chronic prostatitis. Urology. 2002; 60:35-7.

11. Cai T, Mazzoli S, Bechi A, et al. Serenoa repens associated with Urtica dioica (ProstaMEV) and curcumin and quercitin (FlogMEV) extracts are able to improve the efficacy of prulifloxacin in bacterial prostatitis patients: results from a prospective randomised study. Int J Antimicrob Agents. 2009; 33:549-53.

12. Shoskes DA. Use of the bioflavonoid quercetin in patients with longstanding chronic prostatitis. J Am Neutraceutical Assoc. 1999; 2:18.

13. Gupta SC, Patchva S, Aggarwal BB. Therapeutic roles of curcumin: lessons learned from clinical trials. AAPS J 2013; 15:195-218.

14. Kim HW, Ha US, Woo JC, et al. Preventive effect of selenium on chronic bacterial prostatitis. J Infect Chemother. 2012; 18:30-4.

15. Han CH, Yang CH, Sohn DW, et al. Synergistic effect between lycopene and ciprofloxacin on a chronic bacterial prostatitis rat model. Int J Antimicrob Agents 2008; 31 Suppl 1:S102-7.

16. Marzano R, Dinelli N, Ales V, Bertozzi MA. Effectiveness on urinary symptoms and erectile function of Prostamev Plus ${ }^{\circledR}$ vs only extract Serenoa repens. Arch Ital Urol Androl. 2015; 87:25-7.

17. Karlsen M, Hovden AO, Vogelsang P, et al. Bromelain treatment leads to maturation of monocyte-derived dendritic cells but cannot replace PGE2 in a cocktail of IL-1 $\beta, I L-6$, TNF- $\alpha$ and PGE2. Scand J Immunol. 2011; 74:135-43.

18. Barrager E, Schauss AG. Methylsulfonylmethane as a treatment for seasonal allergic rhinitis: additional data on pollen counts and symptom questionnaire. J Altern Complement Med. 2003; 9:15-6.

19. Mehlhorn AJ, Brown DA. Safety concerns with fluoroquinolones. Ann Pharmacother. 2007; 41:1859-66.

20. Trinchieri A. Role of levofloxacin in the treatment of urinary tract infections. Arch Ital Urol Androl. 2001; 73:105-13.

21. Giubilei G, Mondaini N, Crisci A, Raugei A, et al. The Italian version of the National Institutes of Health Chronic Prostatitis Symptom Index. Eur Urol. 2005; 47:805-11.

22. Badia X, Garcia-Losa M, Dal-Re R. Ten-language translation and harmonization of the International Prostate Symptom Score: developing a methodology for multinational clinical trials. Eur Urol. 1997; 31:129-40.

23. Kaplan RM, Bush JW, Berry CC. Health status: types of validity and the index of wellbeing. Health Serv Res. 1976; 11:478-507.

24. Apolone G, Mosconi P. The Italian SF-36 Health Survey: translation, validation and norming. J Clin Epidemiol. 1998; 51:1025-36.

25. Nickel JC, Downey J, Hunter D, Clark J. Prevalence of prostati- tis-like symptoms population based study using the National Institutes of Health chronic prostates symptoms index. J Urol. 2001; 165:843-5.

26. Motrich RD, Cuffini C, Mackern Oberti JP, et al. Chlamydia trachomatis occurrence and its impact on sperm quality in chronic prostatitis patients. J Infect. 2006; 53:175-83.

27. Mazzoli S. Conventional bacteriology in prostatitis patients: microbiological bias, problems and epidemiology on 1686 microbial isolates. Arch Ital Urol Androl. 2007; 79:71-5.

28. Gallelli L, Colosimo M, Tolotta GA, Falcone D, Luberto L, Curto LS, Rende P, Mazzei F, Marigliano NM, De Sarro G, Cucchiara S.Prospective randomized double-blind trial of racecadotril compared with loperamide in elderly people with gastroenteritis living in nursing homes. Eur J Clin Pharmacol. 2010;66:137-44.

29. Serra R, Gallelli L, Buffone G, Molinari V, Stillitano DM, Palmieri $C$, de Franciscis $S$. Doxycycline speeds up healing of chronic venous ulcers. Int Wound J. 2015;12:179-84.

30. de Franciscis S, Gallelli L, Battaglia L, et al. Cilostazol prevents foot ulcers in diabetic patients with peripheral vascular disease. Int Wound J. 2015; 12:250-3.

31. Bernichtein S, Pigat N, Camparo P, et al. Anti-inflammatory properties of Lipidosterolic extract of Serenoa repens (Permixon ${ }^{\circledR}$ ) in a mouse model of prostate hyperplasia. Prostate. 2015; 75:706-22.

32. Latil A, Libon C, Templier $M$, et al. Hexanic lipidosterolic extract of Serenoa repens inhibits the expression of two key inflammatory mediators, MCP-1/CCL2 and VCAM-1, in vitro. BJU Int 2012; 110:E301-7.

33. Bjerklund Johansen TE, Grüneberg RN, Guibert J, et al. The role of antibiotics in the treatment of chronic prostatitis: a consensus statement. Eur Urol. 1998; 34:457-66.

\author{
Correspondence \\ Tommaso Cai, MD (Corresponding Author) \\ ktommy@libero.it \\ Daniele Tiscione, MD \\ Gianni Malossini, MD \\ Department of Urology, Santa Chiara Regional Hospital \\ Largo Medaglie d'Oro, 9, Trento, Italy \\ Luca Gallelli, MD \\ Department of Health Science, School of Medicine, University of Catanzaro, \\ Catanzaro, Italy \\ Paolo Verze, MD \\ Alessandro Palmieri, MD \\ Vincenzo Mirone, MD \\ Department of Urology, University of Naples, Federico II, Naples, Italy \\ Riccardo Bartoletti, MD \\ Department of Urology, University of Pisa, Pisa, Italy
}

